Journal for ImmunoTherapy of Cancer

\title{
ATR inhibitor AZD6738 enhances the antitumor activity of radiotherapy and immune checkpoint inhibitors by potentiating the tumor immune microenvironment in hepatocellular carcinoma
}

\author{
Hailong Sheng, ${ }^{1}$ Yan Huang, ${ }^{1}$ Yazhi Xiao, ${ }^{1}$ Zhenru Zhu, ${ }^{1}$ Mengying Shen, ${ }^{2}$ \\ Peitao Zhou, ${ }^{1}$ Zeqin Guo, ${ }^{1}$ Jian Wang, ${ }^{1}$ Hui Wang, ${ }^{1}$ Wencong Dai, ${ }^{2}$ Wanjun Zhang, ${ }^{3}$ \\ Jingyuan Sun, ${ }^{1}$ Chuanhui Cao (1) ${ }^{1}$
}

\begin{abstract}
To cite: Sheng $\mathrm{H}$, Huang $\mathrm{Y}$, Xiao Y, et al. ATR inhibitor AZD6738 enhances the antitumor activity of radiotherapy and immune checkpoint inhibitors by potentiating the tumor immune microenvironment in hepatocellular carcinoma. Journal for ImmunoTherapy of Cancer 2020;8: 000340. doi:10.1136/jitc-2019-000340

- Additional material is published online only. To view please visit the journal online (http://dx.doi.org/10.1136/jitc2019-000340).
\end{abstract}

HS and YH are joint first authors.

Accepted 29 April 2020

Check for updates

(C) Author(s) (or their employer(s)) 2020. Re-use permitted under CC BY. Published by BMJ.

For numbered affiliations see end of article.

Correspondence to Dr Chuanhui Cao, Department of Radiation Oncology, Southern Medical University Nanfang Hospital, Guangzhou, Guangdong, China; huichuanca0@163.com

Dr Jingyuan Sun, Department of Radiation Oncology, Southern Medical University Nanfang Hospital, Guangzhou, Guangdong, China; 15013050515@163.com

\author{
ABSTRACT \\ Background Radioimmunotherapy has a promising \\ antitumor effect in hepatocellular carcinoma (HCC), \\ depending on the regulatory effect of radiotherapy on \\ tumor immune microenvironment. lonizing radiation (IR)- \\ induced DNA damage repair (DDR) pathway activation \\ leads to the inhibition of immune microenvironment, thus \\ impairing the antitumor effect of radioimmunotherapy. \\ However, it is unclear whether inhibition of the DDR \\ pathway can enhance the effect of radioimmunotherapy. \\ In this study, we aim to explore the role of DDR inhibitor \\ AZD6738 on the combination of radiotherapy and immune \\ checkpoint inhibitors (ICls) in HCC. \\ Methods C57BL/6 mouse subcutaneous tumor model \\ was used to evaluate the ability of different treatment \\ regimens in tumor growth control and tumor recurrence \\ inhibition. Effects of each treatment regimen on \\ the alterations of immunophenotypes including the \\ quantification, activation, proliferating ability, exhaustion \\ marker expression, and memory status were assessed by \\ flow cytometry. \\ Results AZD6738 further increased radiotherapy- \\ stimulated $\mathrm{CD}^{+} \mathrm{T}$ cell infiltration and activation and \\ reverted the immunosuppressive effect of radiation \\ on the number of Tregs in mice xenografts. Moreover, \\ compared with radioimmunotherapy (radiotherapy plus \\ anti-PD-L1 (Programmed death ligand 1)), the addition \\ of AZD6738 boosted the infiltration, increased cell \\ proliferation, enhanced interferon (IFN)- $\gamma$ production ability \\ of TIL (tumor-infiltrating lymphocyte) $\mathrm{CD}^{+} \mathrm{T}$ cells, and \\ caused a decreasing trend in the number of TIL Tregs and \\ exhausted T cells in mice xenografts. Thus, the tumor \\ immune microenvironment was significantly improved. \\ Meanwhile, triple therapy (AZD6738 plus radiotherapy plus \\ anti-PD-L1) also induced a better immunophenotype than \\ radioimmunotherapy in mice spleens. As a consequence, \\ triple therapy displayed greater benefit in antitumor \\ efficacy and mice survival than radioimmunotherapy. \\ Mechanism study revealed that the synergistic \\ antitumor effect of AZD6738 with radioimmunotherapy
}

relied on the activation of cyclic GMP-AMP synthase / stimulator of interferon genes (CGAS/STING) signaling pathway. Furthermore, triple therapy led to stronger immunologic memory and lasting antitumor immunity than radioimmunotherapy, thus preventing tumor recurrence in mouse models.

Conclusions Our findings indicate that AZD6738 might be a potential synergistic treatment for radioimmunotherapy to control the proliferation of HCC cells, prolong survival, and prevent tumor recurrence in patients with HCC by improving the immune microenvironment.

\section{BACKGROUND}

Hepatocellular carcinoma (HCC) is the fifth most common cancer and the second leading cause of cancer-related death worldwide. ${ }^{1}$ The prognosis of patients with HCC is poor because most patients are diagnosed at the advanced stage when surgery and treatment are ineffective. Local therapy for advanced HCC is currently recommended by the National Comprehensive Cancer Network guidelines. Radiotherapy, as an indispensable local treatment method for cancers, plays an increasingly important role in the treatment of inoperable HCC. ${ }^{2-4}$ Radiotherapy combined with systematic treatment has been proven to be an effective strategy in many types of cancers (eg, lung and rectal cancers $).{ }^{5}$ However, the combination of radiotherapy with systematic treatment such as sorafenib, which is a multitarget tyrosine kinase inhibitor and recommended as the first-line treatment for patients with advanced HCC, did not dramatically improve the survival of patients with HCC. ${ }^{6}$ Given the poor prognosis of patients with HCC and 
current limited adjuvant systematic treatments for radiotherapy, novel therapeutic strategies are urgently needed to be explored.

In recent years, immune checkpoint inhibitors (ICIs) have been demonstrated to have a positive therapeutic effect on patients with advanced HCC, by yielding about $20 \%$ disease control rate. ${ }^{78}$ There are increasing substantial preclinical studies showing that radiotherapy combined with ICIs improve the control rate and reduce the recurrence rate of multiple types of cancers, including HCC. ${ }^{9}$ Therefore, it appears that the combination of radiotherapy and ICIs may become a promising treatment intervention for patients with advanced HCC in the future. It is well documented that radiation enhances the curative effect of ICIs by modulating the cancer immune microenvironment. ${ }^{10}$ For example, radiation induces DNA damage in cancer cells and facilitates dsDNA (double-strand DNA) release, thus activating the cGAS/STING signaling pathway; as a consequence, innate immunity is stimulated and lymphocyte infiltration is increased in cancer tissues. ${ }^{11}$ Meanwhile, by destroying cancer cells and promoting the antigen presentation, radiation activates immunity to induce lymphocyte infiltration and improve the efficacy of immunotherapy. ${ }^{12-14}$

However, other than simulative effect, radiation also has suppressive effect on the tumor environment. DNA damage repair (DDR) pathway activation triggered by radiation-induced DNA damage upregulates the expression of CTLA-4 and PD-L1, which creates an immunosuppressive microenvironment in tumor tissues. ${ }^{15}$ Ataxia telangiectasia and Rad3-related protein (ATR) is an essential kinase in the DDR transduction signaling pathway. AZD6738, a specific ATR inhibitor, has been demonstrated to potentiate radiation-induced lymphocyte infiltration and lymphocyte activation in tumor tissues, thus achieving a more potent anticancer effect. ${ }^{16} 17$ Moreover, AZD6738 is currently under investigations in 10 clinical trials in combination with either chemotherapy or radiotherapy. In the light of the previously described information, it is becoming increasingly important to explore whether AZD6738 could increase the therapeutic effect of radiotherapy combined with ICIs therapy. Therefore, the aim of this study is to comprehensively characterize the role of the AZD6738 on the modulation of tumor immune microenvironment and the treatment efficacy of radioimmunotherapy. Our data suggested a novel possible therapeutic approach for patients with advanced HCC, and this treatment paradigm merits evaluation in clinical trials in the future.

\section{METHODS}

\section{Cell culture}

Hepa 1-6 cells (a C57/L murine liver cancer cell line) and H22 cells (a BALB/c murine liver cancer cell line) were obtained from the Shanghai Institute of Biochemistry and Cell Biology. Hepa 1-6 cells were cultured in DMEM (dulbecco's modified eagle medium) with $10 \%$
FBS (fetal bovine serum). H22 cells were cultured in RPMI-1640 (Roswell Park Memorial Institute-1640) medium with $10 \%$ FBS.

\section{Establishment of subcutaneous tumor models}

Female C57BL/6 mice (4-6 weeks old) or BALB/c mice (4-6 weeks old) were provided by the Southern Medical University Animal Center. Hepa 1-6 cells $\left(1 \times 10^{7}\right)$ were implanted subcutaneously in the right hind flank of the C57BL/ 6 mice. H22 cells $\left(5 \times 10^{6}\right)$ were implanted subcutaneously in the right hind flank of the BALB/c mice. Tumor volumes were calculated using a standard formula: length $\times$ width $^{2} / 2$. Radiation was administered when tumors reached approximately $200 \mathrm{~mm}^{3}$. Tumor volume was measured every 5 days. For ethical considerations, mice were sacrificed when the tumor volumes reached $1000 \mathrm{~mm}^{3}$. Endpoint day was designated as the 60 th day after commencement of treatment.

\section{Establishment of orthotopic liver cancer models}

C57BL/6 mice (4-6weeks old) were anesthetized by intraperitoneal injection with $2 \%$ sodium pentobarbital solution. After iodophor disinfection, liver was exposed, and $1 \times 10^{6}$ Hepa 1-6 cells were slowly injected into the liver, followed by closure of the abdominal cavity. MRI was performed to visualize progression of the orthotopic HCC tumor, with treatment administered when the maximum diameter of the tumor reached 3-5 mm. After 40 days of treatment, the mice were sacrificed, and the livers were removed.

\section{Mice treatments}

Mice received three fractions of $6 \mathrm{~Gy}$ on days 1,3 , and 5 from the start of treatment. Imaging and radiation were performed using a small animal radiation research platform (SARRP, Xstrahl). Mice were intragastrically administered AZD6738 (S7693, Selleck; $75 \mathrm{mg} / \mathrm{kg}$ ) on days 1, 3, and 5 from the start of treatment. For the PD-L1 blockade experiment, $200 \mu \mathrm{g}$ anti-PD-L1 (Clone:10F.9G2, Catalog \#: BE0101) was administered intraperitoneally on days 1,4 , and 7 from the start of treatment. Mice were intraperitoneally injected with C-176 (S6575, Selleck; $5 \mathrm{mg}$ / $\mathrm{kg} /$ day) daily from 1 week before radiation until the complete of radiation.

\section{Blood analysis}

Peripheral blood samples were collected from the retroorbital sinus on days 1,4 , and 7 after treatment initiation. Alanine aminotransferase (ALT) and serum creatinine (Scr) were detected using an animal biochemical analyzer.

\section{Statistical analysis}

Statistical comparisons between three or more groups were performed using one-way analysis of variance (ANOVA), followed by Tukey's multiple comparison test. For mouse subcutaneous tumor volume experiments, statistical analysis was performed using mixedeffects model, followed by Tukey's multiple comparison test. Survival curves for different groups of mice were 
generated using the Kaplan-Meier method. Survival data were compared using the log-rank Mantel-Cox test. $\mathrm{P}<0.05$ was considered statistically significant. All graphs were plotted using GraphPad Prism V.7.

\section{RESULTS \\ AZD6738 increases CD8 ${ }^{+} \mathrm{T}$ cell infiltration and activation following radiation}

A previous report showed that inhibition of the DDR pathway reverts radiation-induced PD-L1 upregulation, suggesting that a DDR inhibitor might attenuate a radiation-induced immune microenvironment. We first tested the effect of AZD6738 on the expression level of PD-L1 in HCC cells treated with AZD6738, radiation, or the combination. We found that at 24 and 48 hours, radiation alone significantly upregulated PD-L1 expression (fold-change in PD-L1 median fluorescence intensity \pm SD, radiation vs vehicle: 24 hours, $2.02 \pm 0.15$-fold, $\mathrm{p}<0.0001$; 48 hours, $1.58 \pm 0.20$-fold, $\mathrm{p}<0.0001)$. And the addition of AZD6738 to radiation decreased the radiation-induced PD-L1 upregulation (radiation vs AZD6738 plus radiation: 24 hours, $2.02 \pm 0.15$-fold vs $1.05 \pm 0.02$-fold, $\mathrm{p}<0.0001$; 48 hours, $1.58 \pm 0.20$-fold vs $0.92 \pm 0.07$-fold, $\mathrm{p}<0.0001$ ). At 72 hours, no difference was observed between radiation and AZD6738 with radiation (online supplementary figure 2).

Next, we explored the role of AZD6738 on immune microenvironment in vivo. Hepa 1-6 cells were implanted on the flanks of C57BL/6 mice. When the subcutaneous tumors grew to $200 \mathrm{~mm}^{3}$, we treated the mice with AZD6738, radiation, or the combination. At day 8, radiation alone increased the percentage of tumor-infiltrating lymphocyte (TIL) Tregs $(0.099 \% \pm 0.036 \%$ radiation vs $0.041 \% \pm 0.024 \%$ vehicle, $\mathrm{p}=0.0188$ ). However, AZD6738 plus radiation reduced the percentage of Tregs compared with radiation alone $(0.033 \% \pm 0.015 \%$ AZD6738 plus radiation vs radiation, $\mathrm{p}=0.0072)$. No differences were observed on day 14 (figure 1A). Moreover, addition of AZD6738 to radiation significantly increased the proportion of $\mathrm{CD}^{+} \mathrm{T}$ cells compared with vehicle on day 14 $(65.7 \% \pm 7.6 \%$ AZD6738 plus radiation vs $40.7 \% \pm 2.5 \%$ vehicle, $\mathrm{p}<0.0001$; figure 1B). At days 8 and 14, no differences in the proportion of $\mathrm{CD} 8^{+} \mathrm{T}$ cells were observed between vehicle and radiation.

Next, we determined the activation status of tumorinfiltrating $\mathrm{CD}^{+} \mathrm{T}$ cells. We investigated expression levels of PD- 1 and Tim 3 in CD8 ${ }^{+}$T cells. At day 8, we found that administration of AZD6738 plus radiation significantly downregulated PD-1 expression (fold-change in median fluorescence intensity $\pm \mathrm{SD}$, AZD6738 plus radiation vs vehicle: $0.53 \pm 0.23$-fold; $p=0.0381$ ) but showed no effect on Tim3 expression. At day 14, radiation treatment upregulated Tim3 expression (fold-change in median fluorescence intensity $\pm \mathrm{SD}$, radiation vs vehicle: $1.43 \pm 0.37$-fold; $\mathrm{p}=0.0112$ ), and administration of AZD6738 plus radiation significantly downregulated Tim3 expression (AZD6738 plus radiation: $0.65 \pm 0.39$-fold vs radiation; $\mathrm{p}=0.0413$ ), whereas no differences were observed in PD-1 expression (figure 1C). At day 8, AZD6738 with radiation reduced the percentage of TIL CD $8{ }^{+} \mathrm{PD}-1^{+} \mathrm{T}$ cells in comparison with radiation alone $(11.7 \% \pm 1.2 \%$ AZD6738 plus radiation vs $25.7 \% \pm 3.2 \%$ radiation alone, $\mathrm{p}=0.0227)$. No differences were observed at day 14 (figure 1D).

At day 8, AZD6738 plus radiotherapy increased the percentage of TIL $\mathrm{CD}^{+}{ }^{+} \mathrm{T}$ cells that produced IFN- $\gamma$ compared with radiation alone $(13.9 \% \pm 3.7 \%$ AZD6738 with radiation vs $2.6 \% \pm 1.3 \%$ radiation, $\mathrm{p}=0.0151$ ). At day 14, compared with vehicle, both radiation alone and AZD6738 plus radiation increased the percentage of TIL $\mathrm{CD}^{+} \mathrm{T}$ cells that produced IFN- $\gamma$ (figure $1 \mathrm{E}$ ). In summary, AZD6738 potentiated the effect of radiation on reducing the number of exhausted $\mathrm{T}$ cells and increasing the cell-killing activity of $\mathrm{CD} 8^{+} \mathrm{T}$ cells, meanwhile, reverted radiation-induced Tregs infiltration.

\section{AZD6738 increase the antitumor efficacy of radiation combined with anti-PD-L1 and prolongs tumor-bearing mice survival}

Because AZD6738 improved the radiation-induced immunosuppressive microenvironment, it is possible that its use could also enhance the antitumor effect of radiotherapy combined with ICIs. To determine the treatment efficacy of AZD6738, the Hepa 1-6 and H22 tumor-bearing mice were treated with varied treatment regimens (figure 2A). In Hepa 1-6 tumor-bearing mice models, for vehicle and AZD6738 alone group, the designated tumor volume endpoint $\left(1000 \mathrm{~mm}^{3}\right)$ was reached at days 15 and 20 , respectively. Both radiation alone and anti-PD-L1 alone groups reached the endpoint on day 25. AZD6738 plus radiation group reached the endpoint at day 30 . Until day 35, anti-PD-L1 plus radiation (radioimmunotherapy) group and radiotherapy combined with anti-PD-L1 and AZD6738 (triple therapy) group still did not reach the endpoint yet. Furthermore, compared with radioimmunotherapy, triple therapy significantly inhibited tumor growth (mean tumor volume \pm SEM: $81 \pm 59 \mathrm{~mm}^{3}$ triple therapy vs $369 \pm 147 \mathrm{~mm}^{3}$ radioimmunotherapy, $\mathrm{p}=0.0172$; figure 2B,C). Similarly, in H22-tumor-bearing mouse models, triple therapy significantly inhibited tumor growth relative to radioimmunotherapy (mean tumor volume \pm SEM: $438 \pm 61 \mathrm{~mm}^{3}$ triple therapy vs $771 \pm 72 \mathrm{~mm}^{3}$ radioimmunotherapy; $\mathrm{p}=0.0301$ ) (online supplementary figure 3). In Hepa 1-6 tumor-bearing mice models, the average survival time of vehicle group was 15 days, and these of the AZD6738 alone, anti-PD-L1 alone, and radiation alone groups were 25, 32, and 42 days. Compared with radiation alone, the addition of AZD6738 or anti-PD-L1 to radiation did not further increase the mice survival. Meanwhile, triple therapy significantly prolonged survival compared with radiation alone or radioimmunotherapy. In addition, triple therapy showed higher complete response rate than radioimmunotherapy $(83 \%$ triple therapy vs $58 \%$ radioimmunotherapy; figure $2 \mathrm{D}$ ). Therefore, the addition of AZD6738 to radioimmunotherapy 
Figure 1

A
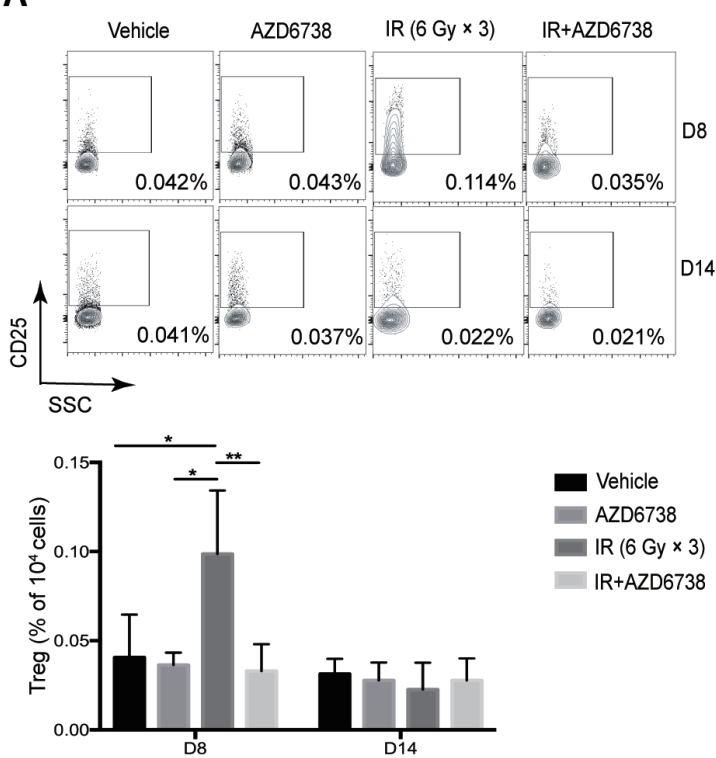

C

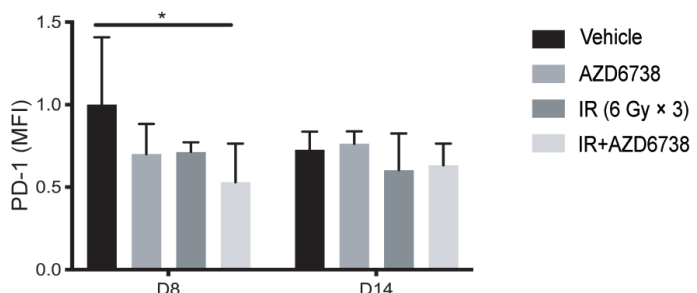

Tumor
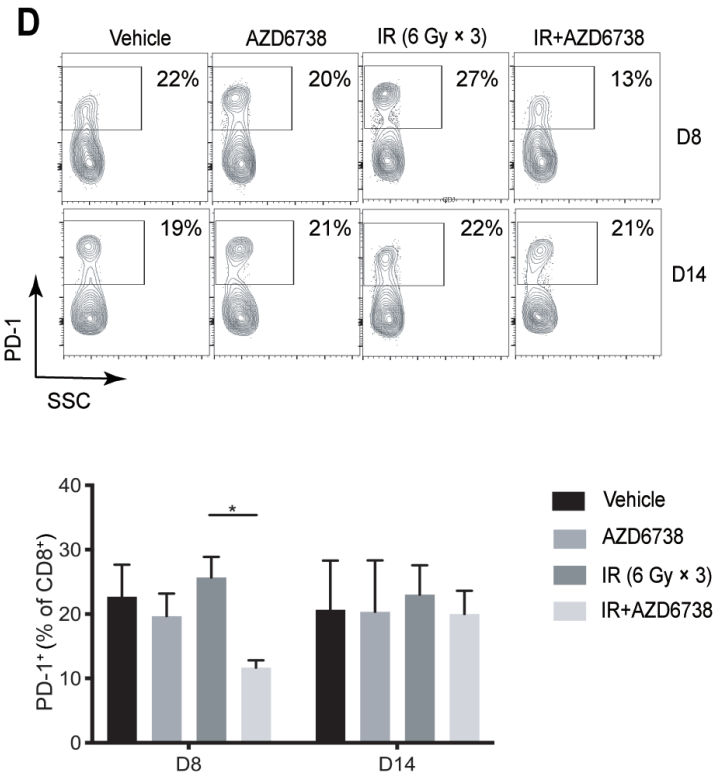

Vehicle

AZD6738

IR $(6$ Gy $\times 3)$

IR+AZD6738
B

Tumor
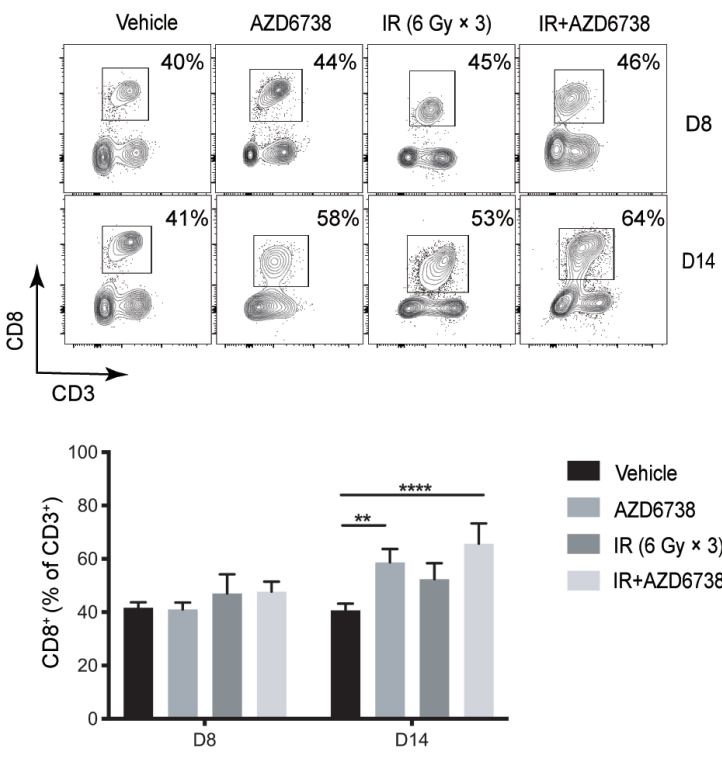

Vehicle

AZD6738

$\operatorname{IR}(6 \mathrm{~Gy} \times 3)$

IR+AZD6738

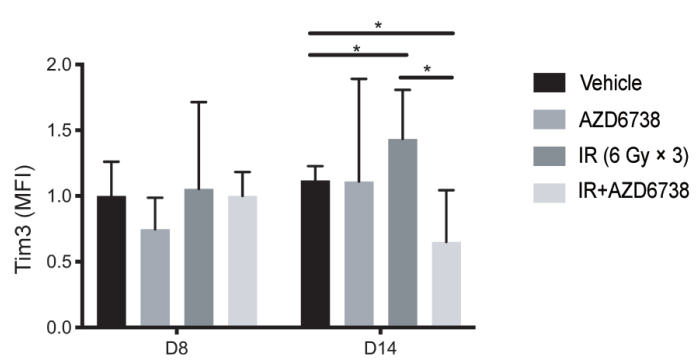

Tumor

E
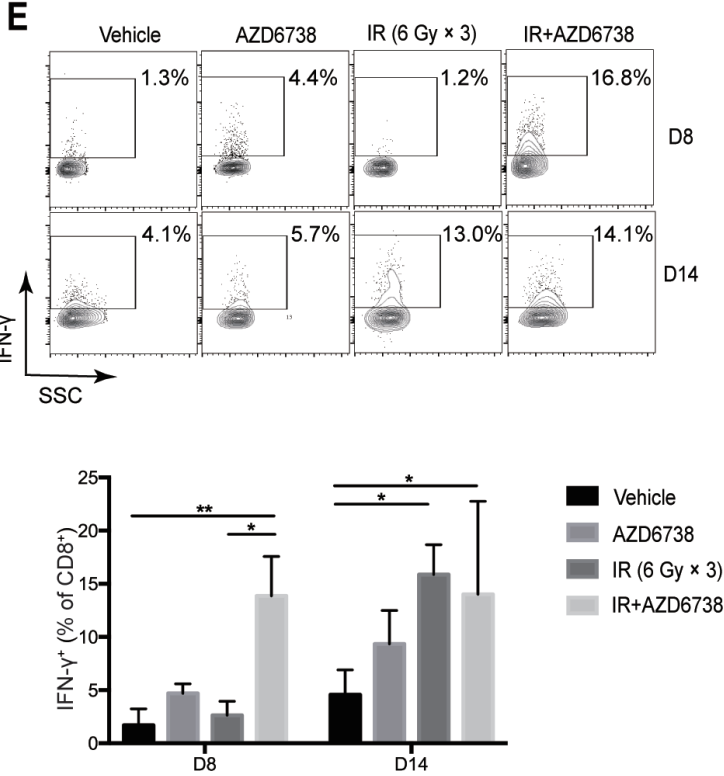

Figure 1 AZD6738 improves immune microenvironment in mice hepatocellular carcinoma (HCC) tissues after radiotherapy. (A) Representative contour plots depicting the percentages of tumor-infiltrating (TIL) Tregs $\left(\mathrm{CD} 25^{+} \mathrm{Foxp} 3^{+}\right)$, and the quantitation of the number of TIL Tregs per $10^{4}$ cells stained at days 8 and 14 was shown. (B) Representative contour plots and quantification of $\mathrm{CD}^{+} / \mathrm{CD} 3^{+}$ratios at days 8 and 14 . (C) Quantitation of PD-1 and Tim3 median fluorescence intensity in TIL CD8 ${ }^{+} \mathrm{T}$ cells at days 8 and 14. (D) Representative contour plots and quantification of the percentage of TIL PD $-1^{+} \mathrm{CD} 8^{+} \mathrm{T}$ cells at days 8 and 14. (E) Representative contour plots and quantification of TIL CD8 ${ }^{+} \mathrm{T}$ cells that elicit IFN- $\gamma$ following stimulation with PMA/ ionomycin at days 8 and 14. Data represent the mean $\pm S D$ for $(A)-(E)$, statistical analysis was performed by using one-way analysis of variance with Tukey's multiple comparisons test. ${ }^{*} p<0.05$; ${ }^{* \star} p<0.005 ;+{ }^{* \star \star \star} p<0.0001$. IFN- $\gamma$, interferon- $\gamma$; IR, ionizing radiation; PMA, phorbol 12-myristate 13-acetate. 
A

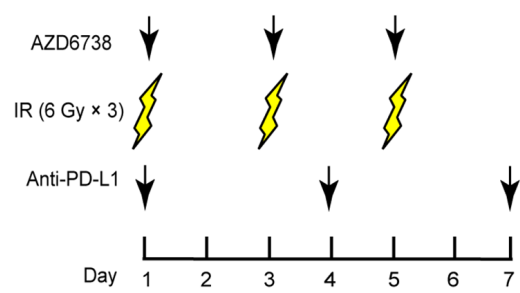

B

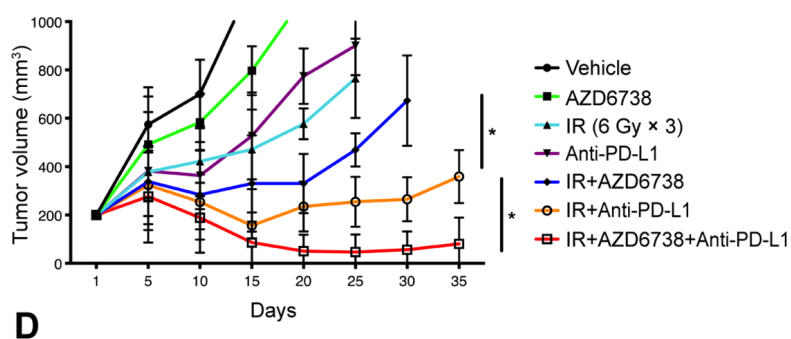

D

C
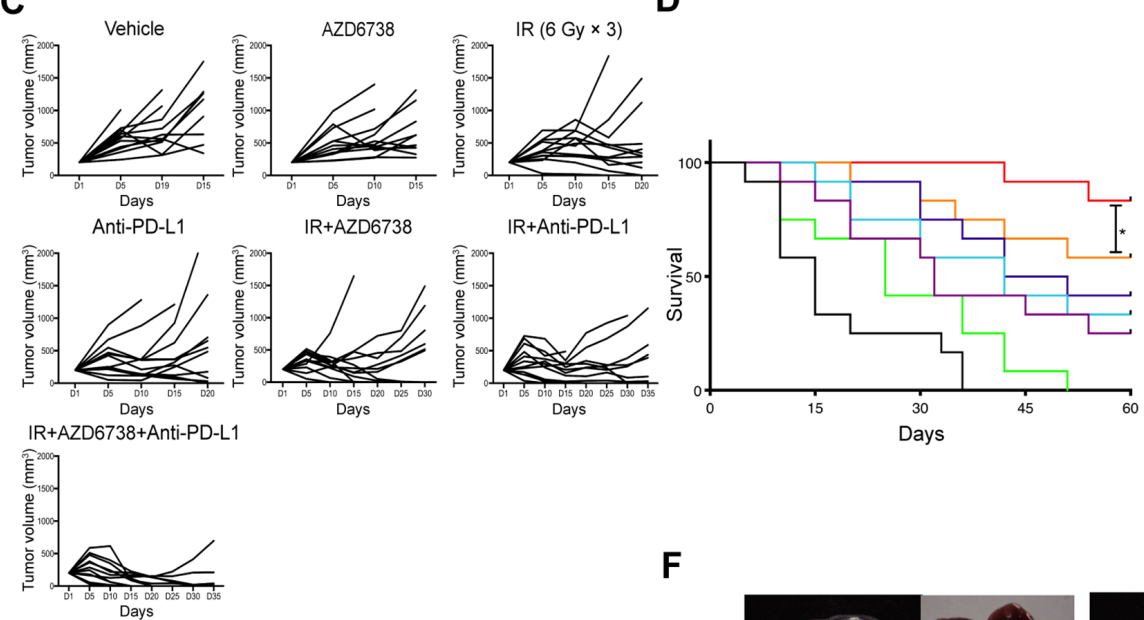

+ Vehicle

- IR (6 Gy x 3)

- Anti-PD-L1

- IR+AZD6738

+ IR+AZD6738+Anti-PD-L1

E
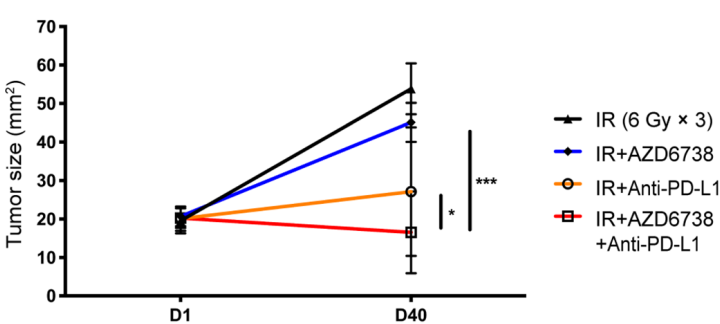

$\rightarrow$ IR+AZD6738

- IR+Anti-PD-L1 IR+AZD6738

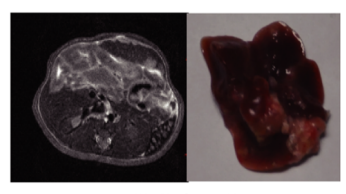

IR $(6 \mathrm{~Gy} \times 3)$

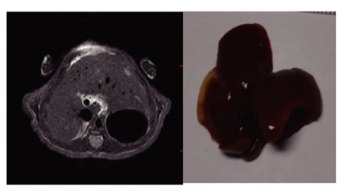

IR+Anti-PD-L1

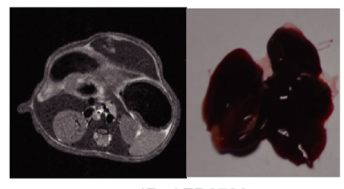

IR+AZD6738

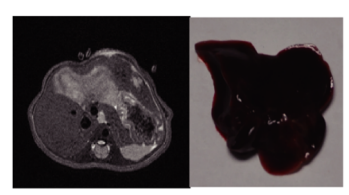

IR+AZD6738+Anti-PD-L1

Figure 2 Addition of AZD6738 potentiates radiation combined with anti-PD-L1 therapy in mice tumor growth control and survival improvement. (A) Schematic showing schedules of ionizing radiation (IR), AZD6738, and anti-PD-L1 treatment. (B-C) Response of the subcutaneous tumors $(B)$ or individual tumor volumes $(C)$ to the indicated treatment regimens. $n=12$ in each group. Data represent the mean \pm SEM. (D) Survival plots for each treatment regimens were shown. (E) Response of the orthotopic hepatocellular carcinoma (HCC) tumors to treatment with the indicated treatment regimens. $n=5$ in each group. Data represent the mean \pm SEM. (F) Representative images of mice liver MRI before treatment and the corresponded isolated liver samples after treatment. For (B), statistical analyses were performed using a mixed-effects model, followed by Tukey's multiple comparison test. For (D), survival data were compared using the log-rank Mantel-Cox test. For (E), statistical analyses were performed using one-way analysis of variance with Tukey's multiple comparisons test. ${ }^{*} p<0.05$; ${ }^{* * *} p<0.0005$.

significantly inhibited tumor growth, increased complete response rate, and prolonged the survival time of mice.

Importantly, to better replicate a clinical scenario, we treated orthotopic HCC-bearing mice with various regimens, subsequently observing that triple therapy exhibited better antitumor efficacy than radioimmunotherapy (mean tumor volume \pm SEM: $16.7 \pm 9.4 \mathrm{~mm}^{3}$ triple therapy vs $32.9 \pm 17.0 \mathrm{~mm}^{3} \quad$ radioimmunotherapy, $\mathrm{p}=0.0421$; figure $2 \mathrm{E}, \mathrm{F})$.

More importantly, the addition of AZD6738 was well tolerated without abnormal levels of ALT and Scr in mice blood samples. These data suggested that AZD6738 increased the antitumor effect of radioimmunotherapy without impairing liver and kidney functions in mice (online supplementary figure 4).

\section{AZD6738 impacts T cell infiltration following radioimmunotherapy}

As the antitumor effect of the triple therapy is better than that of radioimmunotherapy, we need to identify the effect of AZD6738 on the alterations in tumor immune microenvironment. Lymphocytes from the tumors and spleen were collected at days 8 and 14 (figure 3A). At day 14 , both radioimmunotherapy and triple therapy significantly increased the number of TIL CD8 ${ }^{+} \mathrm{T}$ cells compared with radiation alone $(30.2 \pm 15.2$ radiation alone vs $238.8 \pm 124.3$ radioimmunotherapy, $\mathrm{p}=0.0060$; vs 
$350.6 \pm 90.8$ triple therapy, $\mathrm{p}<0.0001$; figure $3 \mathrm{~B}$ ). AZD6738 increased the numbers of TIL $\mathrm{CD}^{+} \mathrm{T}$ cells in triple therapy compared with that of in radioimmunotherapy, but the difference did not reach statistical significance. At day 14, anti-PD-L1 with radiation significantly increased the ratio of $\mathrm{CD}^{+} / \mathrm{CD}^{+} \mathrm{T}$ cells compared with radiation alone $(50.0 \% \pm 3.0 \%$ radiation alone vs $64.2 \% \pm 7.3 \%$ anti-PD-L1 with radiation, $\mathrm{p}=0.0239$; figure $3 \mathrm{C}$ ). Triple therapy further increased the ratio of $\mathrm{CD}^{+} / \mathrm{CD}^{+} \mathrm{T}$ cells compared with anti-PD-L1 with radiation at days 8 and 14 (day $8,61.2 \% \pm 3.0 \%$ triple therapy vs $50.0 \% \pm 5.5 \%$ radioimmunotherapy, $\mathrm{p}=0.0384$; day $14,82.0 \% \pm 8.4 \%$ triple therapy vs $64.2 \% \pm 7.3 \%$ radioimmunotherapy, $\mathrm{p}=0.0046$; figure 3C).

Meanwhile, we examined the effect of AZD6738 on the number of TIL Tregs. On day 8, AZD6738 plus radiation, radioimmunotherapy, and triple therapy significantly inhibited the radiation-induced TIL Tregs infiltration (4.4 \pm 2.1 AZD6738 plus radiation vs $8.9 \pm 2.7$ radiation, $\mathrm{p}=0.0111 ; 2.2 \pm 1.4$ radioimmunotherapy vs radiation, $\mathrm{p}=0.0003 ; 1.1 \pm 1.3$ triple therapy vs radiation, $\mathrm{p}<0.0001$; figure 3D). At days 8 and 14, compared with AZD6738 plus radiation and anti-PD-L1 plus radiation, triple therapy further reduced the number of TIL Tregs, but the difference did not reach statistical significance (figure 3D). Although no difference in the number of TIL Tregs was observed between triple therapy and radioimmunotherapy, triple therapy significantly increased the $\mathrm{CD}^{+} /$Treg ratio at day 14 compared with radioimmunotherapy (191.5 \pm 51.8 triple therapy vs $95.7 \pm 69.6$ radioimmunotherapy, $\mathrm{p}=0.0222$; figure $3 \mathrm{E}$ ). From day 8 to day 14 , the $\mathrm{CD}^{+} /$Treg ratio in the spleen increased in

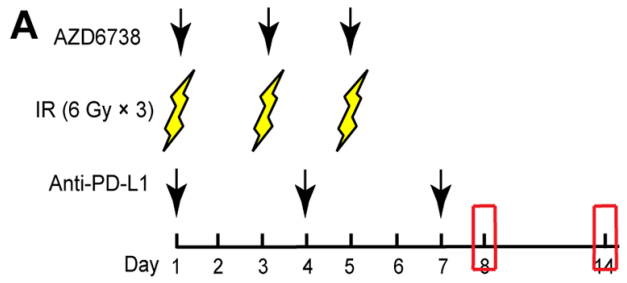

C Tumor

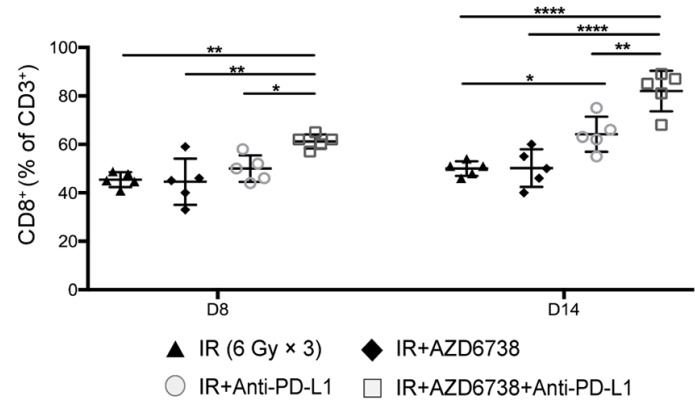

E

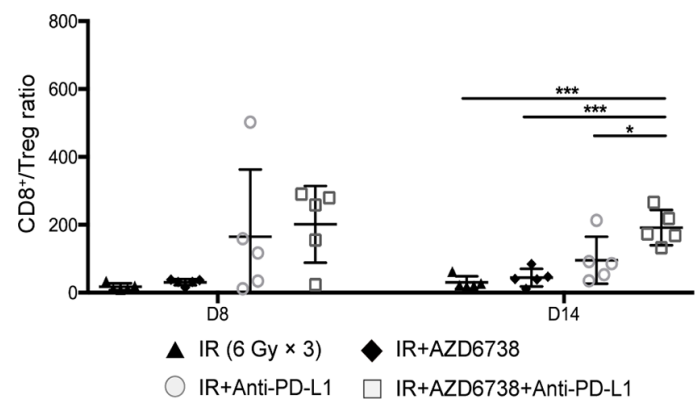

$\Delta \mathrm{IR}(6 \mathrm{~Gy} \times 3) \quad$ IR+AZD 6738

IR+Anti-PD-L1 $\square$ IR+AZD6738+Anti-PD-L1

B

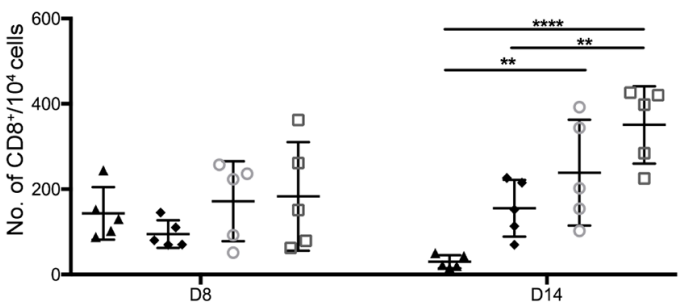

D

Tumor

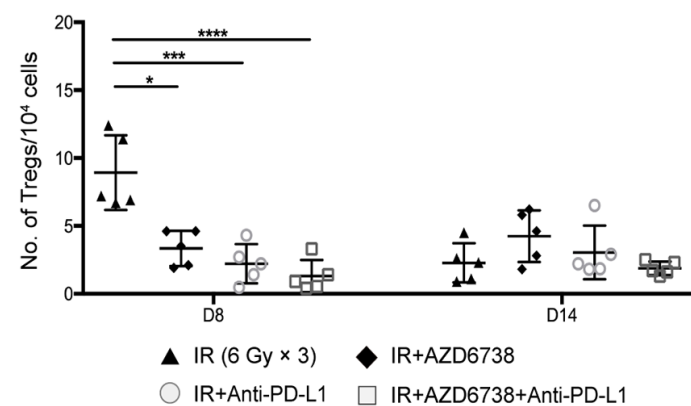

$\mathbf{F}$

Spleen

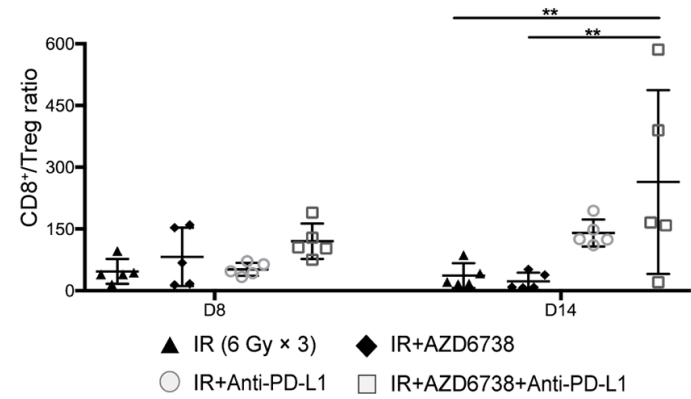

Figure 3 Triple therapy impacts T cell infiltration in mice tumors and spleen. (A) Schematic shows schedules of triple therapy including ionizing radiation (IR), AZD6738, and anti-PD-L1. The red frames indicated the time points for lymphocyte analyses in mice tumors or spleens. (B) Quantitation of the number of tumor-infiltrating lymphocyte (TIL) CD8 ${ }^{+} \mathrm{T}$ cells per $10^{4}$ cells at days 8 and 14. (C) Quantitation of $\mathrm{CD}^{+} / \mathrm{CD}^{+}$ratios in mice tumors. (D) Quantitation of the number of TIL Tregs per $10^{4}$ cells. (E) Quantitation of $\mathrm{CD}^{+} /$Treg ratios in mice tumors. (F) Quantitation of $\mathrm{CD} 8^{+} /$Treg ratios in mice spleens. Data represent the mean $\pm S D$. For $(B)-(F)$, statistical analysis was performed by using one-way analysis of variance with Tukey's multiple comparisons test. ${ }^{\star} \mathrm{p}<0.05 ;{ }^{* \star} \mathrm{p}<0.005 ;{ }^{* \star *} \mathrm{p}<0.0005 ;{ }^{* \star *} \mathrm{p}<0.0001$. 
A

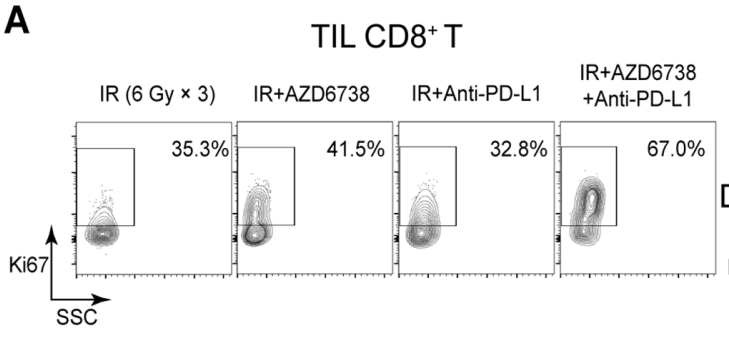

C

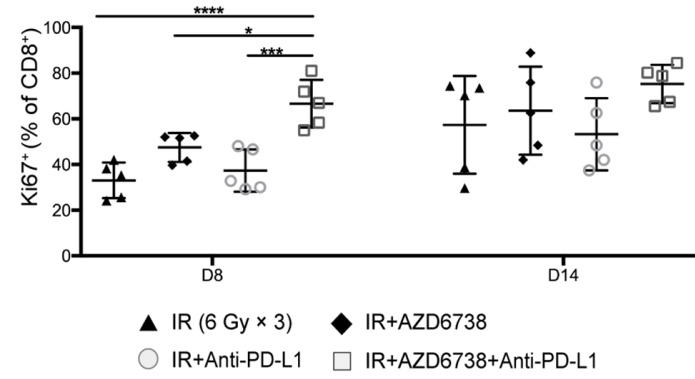

E

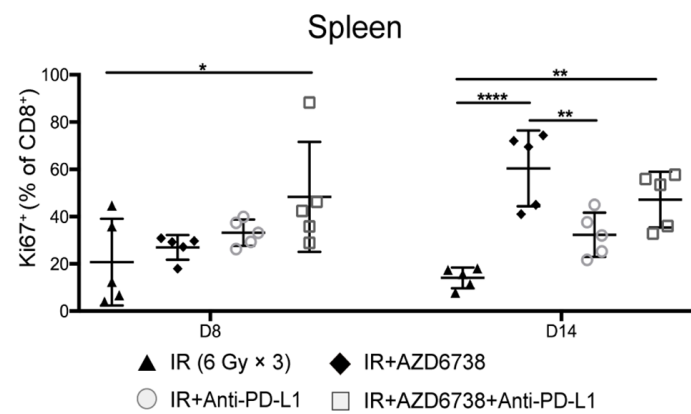

B

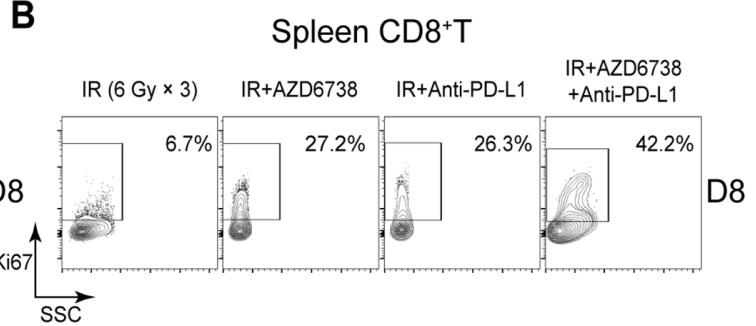

D

Tumor

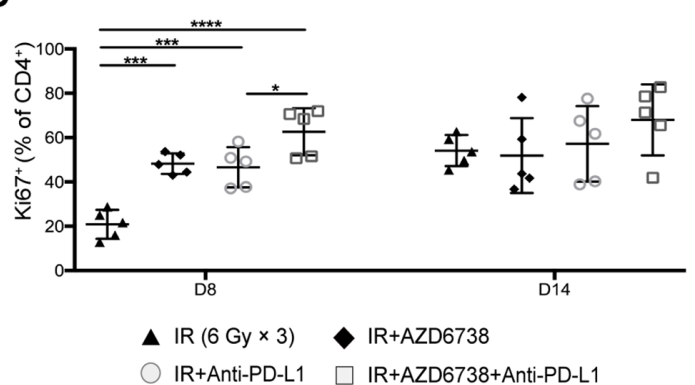

$\mathbf{F}$

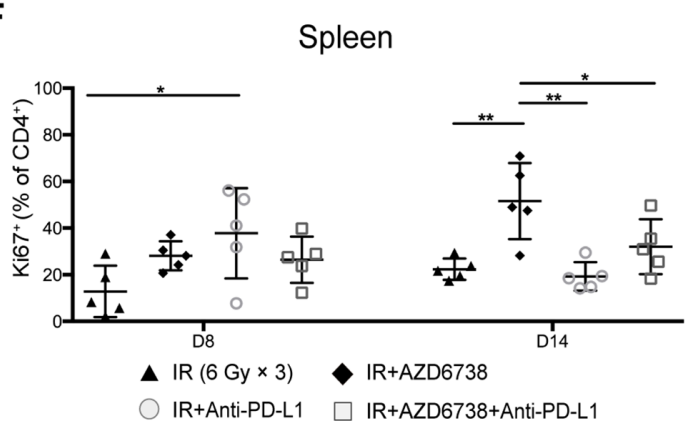

Figure 4 Triple therapy promotes the proliferation of splenic and tumor-infiltrating T cells. (A-B) Representative contour plots of Ki67 $7^{+}$expression on tumor-infiltrating lymphocyte (TIL) and splenic CD8 ${ }^{+} \mathrm{T}$ cells at day 8. (C-D) Quantitation of the percentages of proliferating $\left(\mathrm{Ki} 67^{+}\right)$TIL CD8 ${ }^{+} \mathrm{T}$ cells (C) and TIL CD4 ${ }^{+} \mathrm{T}$ cells (D) at days 8 and 14. (E-F) Quantitation of the percentages of proliferating $\left(K i 67^{+}\right)$splenic $C D 8^{+} T$ cells $(E)$ and splenic $C D 4^{+} T$ cells $(F)$ at days 8 and 14. Data represent the mean $\pm S D$. For $(C)-(F)$, statistical analysis was performed by using one-way analysis of variance with Tukey's multiple comparisons test. ${ }^{*} p<0.05 ;{ }^{* \star} p<0.005 ;{ }^{* \star *} p<0.0005 ;{ }^{* \star *} p<0.0001$. IR, ionizing radiation.

triple therapy. No differences in $\mathrm{CD} 8^{+} /$Treg ratio among different groups were observed on day 8 . At day 14 , only triple therapy significantly upregulated $\mathrm{CD} 8^{+} /$Treg ratio than that of radiation alone group in spleen $(264.1 \pm 223.2$ triple therapy vs $10.2 \pm 5.8$ radiation, $\mathrm{p}=0.0286$; figure $3 \mathrm{~F}$ ).

\section{Triple therapy influences the proliferation of T cells in tumors and spleens of tumor-bearing mice}

Next, we examined the proliferating $\left(\mathrm{Ki} 67^{+}\right)$splenic and TIL T cell population from varied treatments. At day 8 , compared with radiation alone, only triple therapy significantly increased the percentage of TIL $\mathrm{CD}^{+} \mathrm{Ki} 67^{+}$ $\mathrm{T}$ cells $(66.6 \% \pm 10.5 \%$ triple therapy vs $47.5 \% \pm 6.3 \%$ radiation $\mathrm{p}<0.0001$; vs $47.5 \% \pm 6.3 \%$ AZD6738 plus radiation, $\mathrm{p}=0.0136$; vs $37.3 \% \pm 9.3 \%$ radioimmunotherapy, $p=0.0003$; figure $4 A$ ). At day 14, the addition of AZD6738 to radioimmunotherapy did not impact the percentage of TIL $\mathrm{CD} 8^{+} \mathrm{Ki} 67^{+} \mathrm{T}$ cells compared with that of radioimmunotherapy group (figure 4C). Similar phenomena were seen in spleens. Only triple therapy significantly increased the percentage of splenic $\mathrm{CD}^{+} \mathrm{Ki}^{2} 7^{+} \mathrm{T}$ cell at day 8 compared with radiation alone $(60.0 \% \pm 22.2 \%$ triple therapy vs $20.7 \% \pm 18.3 \%$ vehicle, $\mathrm{p}=0.0253)$. No differences were observed at day 14 (figure $4 \mathrm{~B}$ and $\mathrm{E}$ ).

With respect to the percentage of TIL effector (Eff) $\mathrm{T}$ cells, at day 8 , radioimmunotherapy and triple therapy significantly increased the percentage of TIL CD4 $4^{+} \mathrm{Ki} 67^{+}$ Eff T cells compared with radiation alone $(20.9 \% \pm 6.5 \%$ radiation vs $46.6 \% \pm 9.1 \%$ radioimmunotherapy, $\mathrm{p}=0.0006$; vs $42.7 \% \pm 10.9 \%$ triple therapy, $\mathrm{p}<0.0001$; figure $4 \mathrm{D}$ ). Triple therapy further increased this percentage compared with that of radioimmunotherapy group $(46.6 \% \pm 9.1 \%$ radioimmunotherapy vs $42.7 \% \pm 10.9 \%$ triple therapy, $\mathrm{p}=0.0282$; figure $4 \mathrm{D})$. No differences were observed between radioimmunotherapy and triple therapy at day 14 (figure 4D). Furthermore, at day 8 , no differences in the percentage of splenic $\mathrm{Ki} 67^{+} \mathrm{CD} 4^{+}$Eff $\mathrm{T}$ cells were observed between radioimmunotherapy and triple therapy (figure $4 \mathrm{~F}$ ). At day 14, the percentage of $\mathrm{CD} 4^{+} \mathrm{Ki} 67^{+}$Eff $\mathrm{T}$ cells in triple therapy group increased compared with that of 
radioimmunotherapy, but the difference did not reach statistical significance (figure $4 \mathrm{~F}$ ).

\section{Triple therapy attenuates the expression of immune exhaustion markers in $\mathrm{CD}^{+} \mathrm{T}$ cells}

Coexpression of $\mathrm{T}$ cell immune exhaustion markers, including PD-1, Tim-3, and LAG-3, can inhibit $\mathrm{T}$ cell antitumor function. ${ }^{18-21}$ Therefore, we evaluated the expression of $\mathrm{T}$ cell surface immune exhaustion markers in all treatment regimens. At day 8, compared with radiation alone, radioimmunotherapy did not impact the percentage of TIL CD $8^{+} \mathrm{PD}-1^{+} \mathrm{LAG} 3^{+} \mathrm{T}$ cells, whereas triple therapy significantly reduced the percentage of these immunosuppressive $\mathrm{T}$ cells $(2.5 \% \pm 1.6 \%$ triple therapy vs $23.4 \% \pm 17.6 \%$ radiation, $\mathrm{p}=0.0122$; figure $5 \mathrm{~A}$ and $\mathrm{C}$ ). At day 14 , the percentage of TIL CD8 ${ }^{+} \mathrm{PD}-1^{+} \mathrm{LAG}^{+}{ }^{+} \mathrm{T}$ cells was lower in triple therapy than that in AZD6738 plus
A

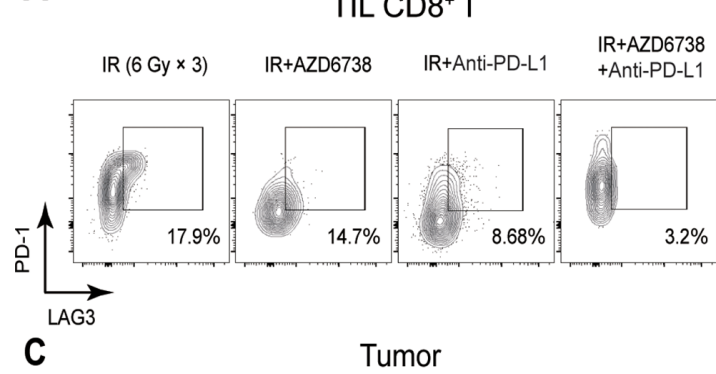

B
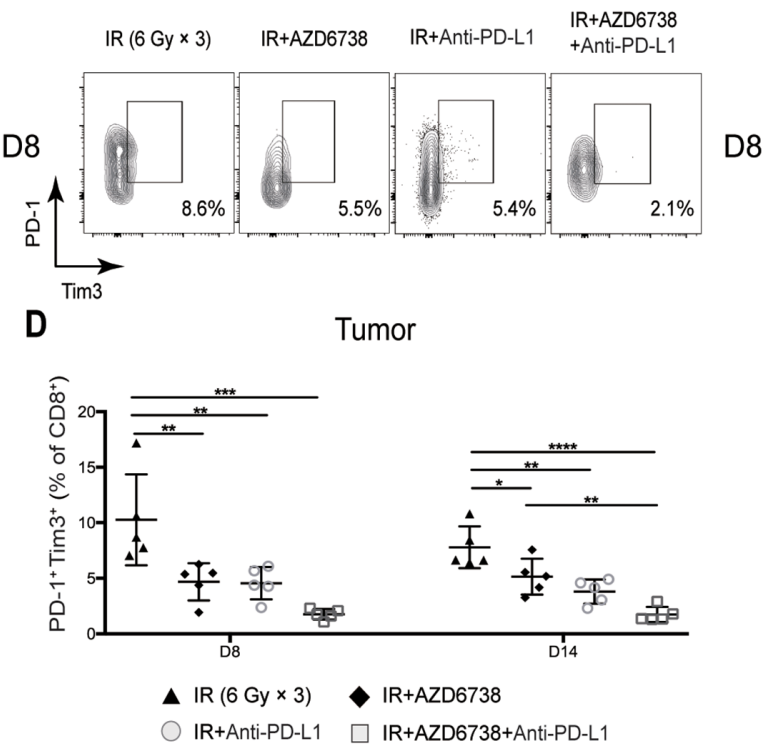

$\mathbf{F}$

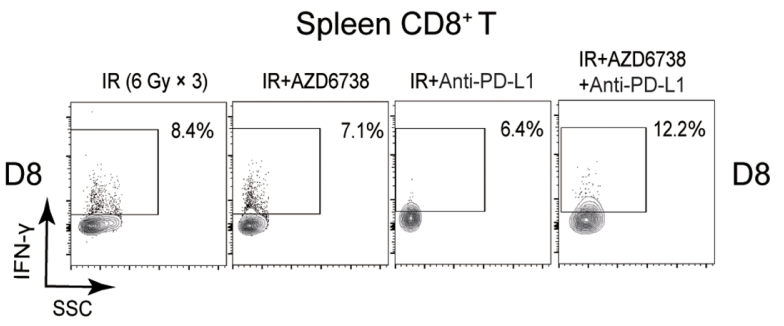

H

Spleen
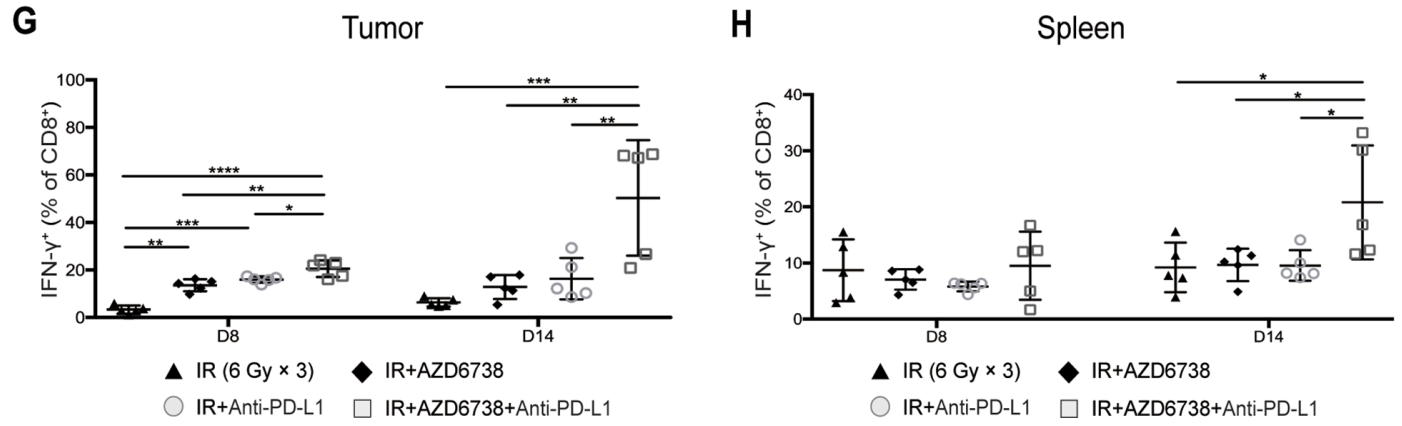

Figure 5 Triple therapy attenuates coexpression of $C D 8^{+} T$ cell exhaustion markers and promotes $C D 8^{+} T$ cell effector function in mice tumors. (A-B) Representative contour plots depicting PD-1 and LAG-3 coexpression and PD-1 and Tim-3 coexpression on tumor-infiltrating lymphocyte (TIL) $\mathrm{CD}^{+} \mathrm{T}$ cells at day 8. (C-D) Quantitation of the percentage of TIL CD8 ${ }^{+} \mathrm{T}$ cells coexpressing PD-1 and LAG-3 (C), and PD-1 and Tim-3 (D) at days 8 and 14. (E-F) Representative contour plots depicting IFN- $\gamma$ expressing $\mathrm{CD}^{+} \mathrm{T}$ cells in mice spleens and tumors following stimulation with PMA/ionomycin at day 8. (G-H) Quantitation of the percentage of TIL $(G)$ and splenic $(H) C D 8^{+} T$ cells that expressed IFN- $\gamma$ at days 8 and 14. Data represent the mean \pm SD. For $(C),(D),(G)$ and $(H)$, statistical analysis was performed by using one-way analysis of variance with Tukey's multiple comparisons test. ${ }^{*} \mathrm{p}<0.05 ;{ }^{* *} \mathrm{p}<0.005 ;{ }^{* * *} \mathrm{p}<0.0005 ;{ }^{* \star \star *} \mathrm{p}<0.0001$. IFN $-\gamma$, interferon- $\gamma$; IR, ionizing radiation. 
radiation group or radioimmunotherapy group, although statistical differences were not achieved (figure 5C).

At day 8, we observed no differences in PD-1 or Tim3 expression. At day 14, we found that triple therapy significantly downregulated Tim3 expression (fold-change in median fluorescence intensity $\pm \mathrm{SD}$, triple therapy vs radiation: $0.43 \pm 0.18$-fold; $p=0.103$ ), whereas no differences were observed in PD-1 expression (online supplementary figure 5A,B. Triple therapy maintained a lower percentage of TIL CD8 ${ }^{+} \mathrm{PD}-1^{+}{ }^{+} \mathrm{Tim} 3^{+}$T cells compared with AZD6738 plus radiation and radioimmunotherapy, but the difference did not reach statistical significance (figure 5B,D). There were no differences in the percentage of CD8 ${ }^{+} \mathrm{PD}$ $1^{+} \mathrm{LAG}^{+}$and $\mathrm{CD}^{+}{ }^{+} \mathrm{PD}-1^{+} \mathrm{Tim}^{+}{ }^{+} \mathrm{T}$ cells between triple therapy and radioimmunotherapy in the spleens (online supplementary figure $5 \mathrm{C}$ and $\mathrm{D}$ ). In summary, compared with radioimmunotherapy, triple therapy can further reduce the coexpression of $\mathrm{CD}^{+} \mathrm{T}$ cell exhaustion markers in mice xenograft tumors and spleens.

\section{Triple therapy promotes $\mathrm{CDB}^{+} \mathrm{T}$ cell effector function in mice tumors and spleens}

To confirm whether the addition of AZD6738 to radioimmunotherapy can enhance effector function after reducing coexpression exhaustion markers of $\mathrm{CD} 8^{+} \mathrm{T}$ cells, we used phorbol 12-myristate 13-acetate (PMA) and ionomycin to stimulate IFN- $\gamma$ production of $\mathrm{CD}^{+} \mathrm{T}$ cells. At day 8 , adding either AZD6738 or anti-PD-L1 to radiation significantly increased the percentage of TIL CD8 ${ }^{+} \mathrm{T}$ cells that produced IFN- $\gamma$, and triple therapy further increases this percentage $(20.5 \% \pm 3.5 \%$ triple therapy vs $13.6 \% \pm 2.6 \%$ AZD6738 plus radiation, $\mathrm{p}=0.0024$; vs $15.6 \% \pm 2.1 \%$ radioimmunotherapy, $\mathrm{p}=0.0317$; figure $5 \mathrm{E}, \mathrm{G})$. At day 14 , the percentage of TIL $\mathrm{CD}^{+} \mathrm{T}$ cells that produced IFN- $\gamma$ remained the same as that of day 8 in mice treated with radiation alone, AZD6738 with radiation, and radioimmunotherapy; however, that of triple therapy was further increased, and it was significantly higher than that of the other treatment groups $(50.3 \% \pm 24.3 \%$ triple therapy vs $6.4 \% \pm 1.8 \%$ radiation, $\mathrm{p}=0.0004$; vs $12.8 \% \pm 5.0 \%$ AZD 6738 with radiation, $\mathrm{p}=0.0019 \mathrm{vs} 16.3 \% \pm 8.7 \%$ radioimmunotherapy, $\mathrm{p}=0.0044$; figure $5 \mathrm{G}$ ).

With respect to the percentage of $\mathrm{CD}^{+} \mathrm{T}$ cells that produced IFN- $\gamma$ in mice spleens, no differences were observed among all treatments at day 8 (figure $5 \mathrm{~F}, \mathrm{H}$ ). At day 14, the percentage in triple therapy was significantly higher than that in the other treatment groups $(20.8 \% \pm 10.2 \%$ triple therapy vs $9.2 \% \pm 4.4 \%$ radiation, $\mathrm{p}=0.0308 \mathrm{vs} 9.7 \% \pm 2.9 \%$ AZD6738 plus radiation, $\mathrm{p}=0.0392$; vs $9.6 \% \pm 2.7 \%$ radioimmunotherapy, $\mathrm{p}=0.0369$; figure $5 \mathrm{H})$.

We additionally examined the percentage of TIL $\mathrm{CD}^{+} \mathrm{T}$ cells that produced IFN- $\gamma$. No differences were observed between radioimmunotherapy and triple therapy at day 8 (online supplementary figure 6A). At day 14 , the percentage of TIL CD4 $4^{+} \mathrm{T}$ cells that produced IFN- $\gamma$ in triple therapy was significantly higher than that in each treatment groups $(51.0 \% \pm 22.9 \%$ triple therapy vs $10.0 \% \pm 2.2 \%$ radiation, $\mathrm{p}=0.0003$; vs $16.0 \% \pm 4.8 \%$ AZD6738 plus radiation, $\mathrm{p}=0.0012$; vs $13.9 \% \pm 0.9 \%$ radioimmunotherapy, $\mathrm{p}=0.0007$; online supplementary figure $6 \mathrm{~A})$. Meanwhile, no differences in the percentage of splenic $\mathrm{CD} 4^{+} \mathrm{T}$ cells that produced IFN- $\gamma$ were observed between radioimmunotherapy and triple therapy at any time points (online supplementary figure 6B). In summary, the addition of AZD6738 to radioimmunotherapy significantly increased the percentage of $\mathrm{CD}^{+}$ and $\mathrm{CD} 4^{+} \mathrm{T}$ cells that produced IFN- $\gamma$ in tumors and the spleen.

\section{AZD6738 promotes the antitumor effect of radioimmunotherapy via activating cGAS/STING signaling pathway}

We then explored the mechanism underlying the synergistic effect of AZD6738 and radioimmunotherapy. Previous studies showed that radiation-induced DNA damage activates cGAS/STING signaling; therefore, we hypothesized that AZD6738, as a DDR inhibitor, might play a role in enhancing cGAS/STING activation. Analysis of levels of several key factors involved in cGAS/ STING signaling in Hepa 1-6 subcutaneous tumors from mice treated with radioimmunotherapy or triple therapy revealed that AZD6738 plus radioimmunotherapy treatment increased levels of cGAS, p-STING, and p-TBK1, suggesting that AZD6738 increased activation of the cGAS/STING pathway (figure 6A). Furthermore, treatment of Hepa 1-6 tumor-bearing mice with the STING inhibitor C-176 impaired the antitumor efficacy of triple therapy (482.4 \pm 72.9 (triple therapy plus STING inhibitor) vs $80.5 \pm 31.4$ (triple therapy), $\mathrm{p}<0.0001$; vs $265.2 \pm 27.4$ (radioimmunotherapy), $\mathrm{p}=0.0003$ ) (figure $6 \mathrm{~B}$ ). These data indicate that AZD6738 exerted a synergistic antitumor effect with radioimmunotherapy by activating cGAS/STING signaling.

\section{Triple therapy enhances immune memory activation in mice tumors and spleens}

We analyzed the memory status of $\mathrm{CD}^{+}$and $\mathrm{CD} 4^{+}$Eff $\mathrm{T}$ cells in mice tumors and spleens. At day 8, compared with radioimmunotherapy, triple therapy increased the percentage of TIL CD8 ${ }^{+}$central memory $\mathrm{T}\left(\mathrm{T}_{\mathrm{CM}}\right)$ cells $(25.5 \% \pm 3.9 \%$ triple therapy vs $17.4 \% \pm 5.6 \%$ radioimmunotherapy, $\mathrm{p}=0.0287$; figure $7 \mathrm{~A}, \mathrm{~B})$. In addition, triple therapy reduced the percentage of TIL $\mathrm{CD} 8^{+}$effector memory $\mathrm{T}\left(\mathrm{T}_{\mathrm{EM}}\right)$ cells $(63.5 \% \pm 4.8 \%$ triple therapy vs $75.4 \% \pm 6.9 \%$ radioimmunotherapy, $\mathrm{p}=0.0433)$. At day 14 , no differences in the percentage of TIL CD8 ${ }^{+} \mathrm{T}_{\mathrm{CM}}$ were observed between radioimmunotherapy group and triple therapy group (figure 7B). The percentage of TIL CD8 ${ }^{+} \mathrm{T}_{\mathrm{EM}}$ cells in triple therapy was significantly elevated compared with that in radioimmunotherapy at day 14 $(83.7 \% \pm 3.8 \%$ triple therapy vs $72.4 \% \pm 6.6 \%$ radioimmunotherapy, $\mathrm{p}=0.0169$; figure $7 \mathrm{C}$ ). No significant differences in activation or memory status of TIL $\mathrm{CD}^{+} \mathrm{T}$ cells were observed between radioimmunotherapy group and 
Figure 6

A

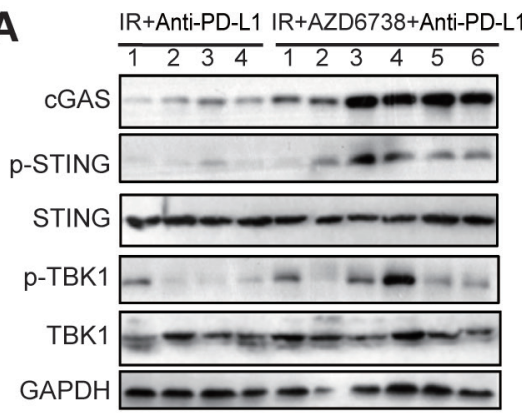

B

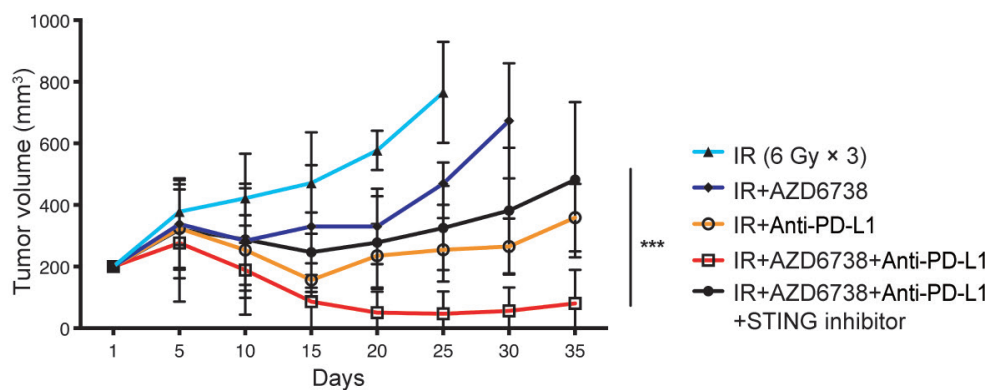

Figure 6 AZD6738 promotes radioimmunotherapy antitumor effect via activating cGAS/STING signaling pathway. (A) Several key proteins of cGAS/STING pathway were detected in Hepa 1-6 subcutaneous tumors from mice treated with radioimmunotherapy or triple therapy group. (B) Response of the Hepa 1-6 subcutaneous tumors to the indicated treatments. $\mathrm{n}=12$ in each group. Data represent the mean \pm SEM. Statistical analysis was performed by using mixed-effects model, followed by Tukey's multiple comparison test. ${ }^{* \star} \mathrm{p}<0.0005$. IR, ionizing radiation.

triple therapy group at any time points (online supplementary figure 7).

At day 14, we found there was no differences in the percentage of splenic $\mathrm{CD}^{+} \mathrm{T}_{\mathrm{CM}}$ cells between radioimmunotherapy group and triple therapy group (online supplementary figure 8A). Meanwhile, the percentage of splenic $\mathrm{CD}^{+} \mathrm{T}_{\mathrm{EM}}$ cells was higher in triple therapy group compared with that in radioimmunotherapy group $(43.6 \% \pm 16.2 \%$ triple therapy vs $22.0 \% \pm 2.7 \%$ radioimmunotherapy, $\mathrm{p}=0.0065$; online supplementary figure $8 \mathrm{~B}$ ). Similar effects were seen in the percentage of splenic $\mathrm{CD}^{+} \mathrm{T}_{\mathrm{CM}}$. The percentage of splenic $\mathrm{CD} 4^{+}$ $\mathrm{T}_{\mathrm{CM}}$ cells in triple therapy increased over time, and it was significantly higher in triple therapy than that in the other treatments at day 14 (online supplementary figure 8C). With respect to the percentage of splenic $\mathrm{CD}^{+} \mathrm{T}_{\mathrm{EM}}$ cells, it was significantly higher in triple therapy group than that in radioimmunotherapy group at day 8
A

\section{TIL CD8 ${ }^{+} \mathrm{T}$}

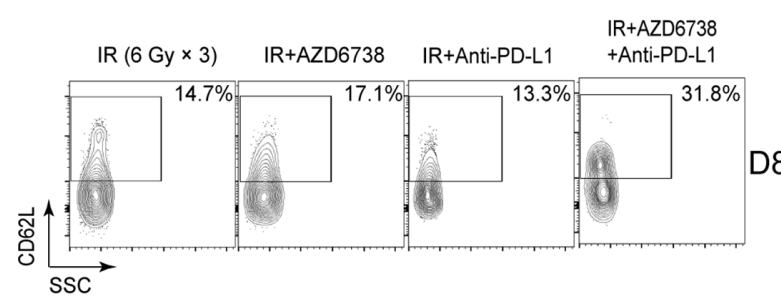

c

Tumor

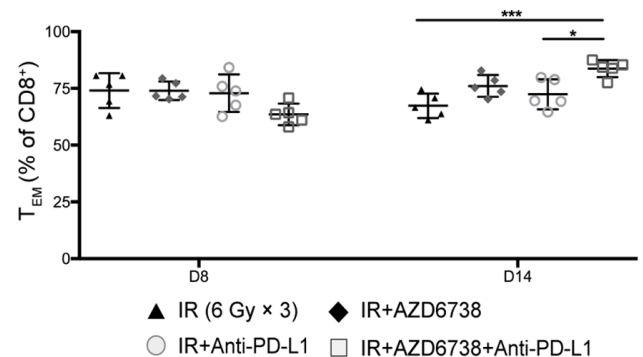

B

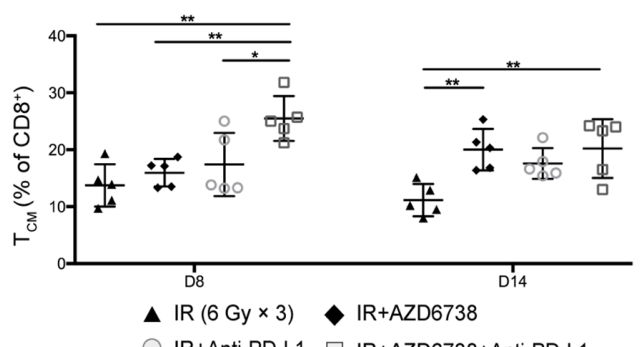

D

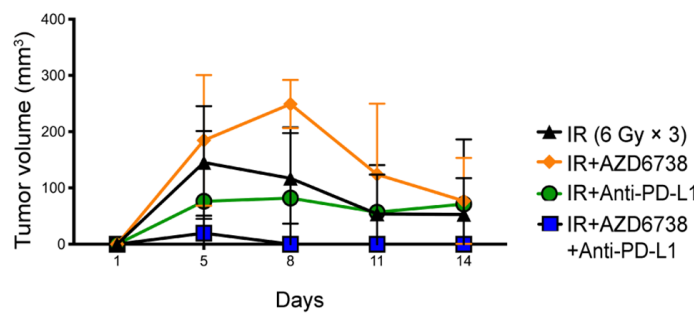

Figure 7 Triple therapy promotes immune memory activation in mice tumors. (A) Representative contour plots depicting CD62L and CD44 expression in tumor-infiltrating lymphocyte (TIL) CD8 ${ }^{+} T$ cells at day 8. (B-C) Quantitation of the percentage of TIL CD8 ${ }^{+} T$ cell central memory $\left(\mathrm{T}_{\mathrm{CM}}, \mathrm{CD}_{2} \mathrm{~L}^{+} \mathrm{CD} 44^{+}\right)$cells or effector memory $\left(\mathrm{T}_{\mathrm{EM}}, \mathrm{CD} 62 \mathrm{~L}^{-} \mathrm{CD} 44^{+}\right)$cells at days 8 and 14. (D) Mice tumors were re-challenged with Hepa 1-6 cells in the contralateral flank on the 20th day. Data represent the curve for the mean tumor volumes. Data represent the mean \pm SD. For (B) and (C), statistical analysis was performed by using one-way analysis of variance with Tukey's multiple comparisons test. For (D), statistical analysis was performed using mixed-effects model, followed by Tukey's multiple comparison test. ${ }^{*} p<0.05 ;{ }^{* \star} p<0.005 ;{ }^{* \star *} p<0.0005$. IR, ionizing radiation. 
$(55.7 \% \pm 7.3 \%$ triple therapy vs $20.7 \% \pm 2.7 \%$ radioimmunotherapy, $\mathrm{p}<0.0001$; online supplementary figure $8 \mathrm{D}$ ). Meanwhile, no differences in the percentage of splenic $\mathrm{CD}^{+} \mathrm{T}_{\mathrm{EM}}$ were observed between radioimmunotherapy and triple therapy at day 14 (online supplementary figure 8D).

As the activation and memory status of $\mathrm{CD} 8^{+}$and $\mathrm{CD} 4^{+}$ Eff $T$ cells is closely related to tumor control, next we determined the effect of AZD6738 on tumor recurrence. We re-challenged the treatment completed tumor-bearing mice with Hepa 1-6 cells in the contralateral flank on the 20th day, and then monitored the tumor volumes of these mice treated with different regimens. We found that, compared with radioimmunotherapy, triple therapy showed a more potent inhibitory effect on the secondary tumor growth (figure 7D). These findings indicated that triple therapy enhanced immunologic memory and prevented recurrence of HCC by boosting $\mathrm{T}_{\mathrm{CM}}$ and $\mathrm{T}_{\mathrm{EM}}$ cells in mice tumors and spleens.

\section{DISCUSSION}

In our study, we found that radiation obviously upregulated the expression of PD-L1 in HCC cells, increased the number of Tregs, the $\mathrm{CD} 8^{+} / \mathrm{CD}^{+} \mathrm{T}$ lymphocyte ratio and the amount of IFN- $\gamma^{+} \mathrm{CD} 8^{+}$T lymphocytes in subcutaneous tumor immune microenvironment. Previous studies have shown that radiation activated $\mathrm{CD}^{+} \mathrm{T}$ cells in tumor tissues by killing tumor cells and releasing antigens from these cells. ${ }^{22}$ However, besides the positive effect on tumor immune microenvironment, radiation also improved to confer negative effect by activating DDR signal pathway, then upregulating PD-L1 expression in tumor cells and increasing infiltration of inhibitory lymphocytes (such as Tregs) in tumor tissues. ${ }^{23-26}$ These studies suggest that radiation has dual roles in modulating tumor immune microenvironment, which is consistent with our findings.

The regulative role of radiation in tumor immune microenvironment provides the rational for radioimmunotherapy, which has been widely studied in the field of tumor therapy. ${ }^{27}$ Numerous preclinical studies have shown the promising antitumor effect of radioimmunotherapy in several cancers including lung cancer, melanoma, and pancreatic cancer, by improving the tumor immune microenvironment. ${ }^{27-30}$ Moreover, two preclinical studies have shown that radioimmunotherapy increased the number and IFN- $\gamma$ secretion of TIL $\mathrm{CD} 8^{+} \mathrm{T}$ cells and improved the local control rate of HCC. ${ }^{31}$ Importantly, several clinical trials regarding lung cancer have indicated the benefit of radioimmunotherapy on patient's survival. For example, the PACIFIC trial and KEYNOTE-001 trial revealed that ICIs improved progression-free survival and overall survival of patients with unresectable stage III non-small cell lung cancer (NSCLC) who previously received chemoradiotherapy. ${ }^{32} 33$ Even though radioimmunotherapy displayed a promising antitumor treatment benefit on NSCLC, clinical trials to investigate the efficacy of radioimmunotherapy on patients with HCC are still ongoing and the results are immature.

Radiation-induced DNA damage promotes the expression of immunosuppressive molecules including PD-L1 and increases immunosuppressive cells in tumor tissues, by activating ATR signaling pathway. ${ }^{15}$ It is well documented that, compared with radiation alone, the addition of AZD6738 increased the number and the IFN- $\gamma$ secreting ability of TIL CD $8^{+}$T lymphocytes. ${ }^{16} 17$ However, as for the Hepa 1-6 subcutaneous xenograft model in our study, we found that although there is a trend that tumor control rate and survival of mice treated with radiation plus AZD6738 was higher than the mice treated with radiation alone, the difference did not reach statistical significance. These findings are inconsistent with what Vendetti et al reported that radiotherapy combined with AZD6738 prolonged the survival time of CT26 tumorbearing mice. ${ }^{16}$ Although such discrepancy remains unclear, one possible explanation for it may be due to the distinct cancer types we focused. In our case, we studied HCC, whereas Vendetti et al studied colorectal cancers. However, as for the alterations of TILs, we found that, compared with radiation alone, AZD6738 plus radiation significantly decreased the number of Tregs, increased the ratio of $\mathrm{CD}^{+} / \mathrm{CD}^{+} \mathrm{T}$ cells, and the number of IFN- $\gamma^{+} \mathrm{CD}^{+}$lymphocytes in Hepa 1-6 tumor tissues. Although the survival time of mice was not extended by the addition of AZD6738 to radiation, tumor immune microenvironment was significantly improved, suggesting that AZD6738 could be a suitable synergistic treatment for radioimmunotherapy. In our study, we found that the combination of AZD6738 with radioimmunotherapy was not only well tolerated by HCC tumor-bearing mice, but also conferred better tumor control and prolonged mice survival.

It has been well reported that radiation combined with ICIs had a strong immunostimulatory effect, including increasing the number of $\mathrm{CD}^{+} \mathrm{T}$ cells, enhancing the activity of $\mathrm{CD}^{+} \mathrm{T}$ cells, and reducing the number of immunosuppressive cells such as Tregs. Consistent with these findings, the similar phenomenon was shown in our case, which may contribute to the better tumor control and survival in mice treated with radiation combine with anti-PD-L1 compared with the mice treated with radiation alone. Intriguingly, in our study, we found that the levels of $\mathrm{CD}^{+} \mathrm{T}$ cells and IFN- $\gamma^{+} \mathrm{CD} 8^{+} \mathrm{T}$ cells remained the same at days 8 and 14 . However, the addition of AZD6738 to radioimmunotherapy progressively boosted the infiltration and activation of $\mathrm{CD} 8^{+} \mathrm{T}$ cells with time in mice tumor tissues. These findings implied that AZD6738 has the potential ability to mediate robust immunostimulatory effects that could synergize with radioimmunotherapy in tumor control and survival improve.

AZD6738 was reported to trigger innate immune cell infiltration through activation of cGAS/STING pathway, which shed light on the possibility that the blockage of cGAS/STING signaling pathway could weaken the antitumor effect of AZD6738. ${ }^{17}$ In our study, we found that 
the combination of AZD6738 with radioimmunotherapy led to the activation of cGAS/STING pathway. More importantly, STING inhibitor C-176 impaired the antitumor efficacy of triple therapy in tumor-bearing mice.

$\mathrm{T}_{\mathrm{CM}}$ cells play a very important role in preventing tumor recurrence and metastasis. Due to the self-renew property and the long survival in vivo, $\mathrm{T}_{\mathrm{CM}}$ cells are able to be rapidly activated and differentiate into effective $\mathrm{T}$ cells on the re-exposure stimulation of tumor antigens. As a result, tumor cells are killed, and tumor recurrence or metastasis is prevented. ${ }^{34} 35$ Thus, the increase in number of memory $\mathrm{T}$ cells can provide better protection for patients with cancer. Several studies have shown that radiation combined with ICIs or AZD6738 increased the number of $T_{C M}$ cells and prevent tumor recurrence and metastasis. ${ }^{1627}$ In our study, compared with radioimmunotherapy, the percentage of TIL CD8 ${ }^{+} \mathrm{T}_{\mathrm{CM}}$ cells was higher following triple therapy, which may contribute to the delayed tumor recurrence in mice treated with triple therapy.

Several clinical studies are being conducted to explore the effect of ATR inhibitors combined with DNAdamaging therapeutic interventions including radiotherapy or chemotherapy in varied types of tumors. ${ }^{36-38}$ In this study, ATR inhibitor AZD6738 did not enhance the HCC control rate of radiotherapy. However, AZD6738 dramatically promoted radioimmunotherapy-induced $\mathrm{CD}^{+}$lymphocyte infiltration and activity, reduced the number of Tregs, and increased memory $\mathrm{T}$ cell infiltration in HCC xenograft tumors. Remarkably, AZD6738 in combination with radioimmunotherapy was well tolerated, prolong survival, and delayed recurrence of the tumor-bearing mice.

Taken all these benefits of AZD6738 combined with radioimmunotherapy together, our data implicated that AZD6738 could be a promising synergetic treatment for radioimmunotherapy in patients with HCC. Although our study was of high clinical significance, the combination of AZD6738 with radioimmunotherapy merits evaluation on clinical trials in patients with HCC.

\section{CONCLUSIONS}

In summary, we have demonstrated that the addition of AZD6738 to radioimmunotherapy increased the infiltration of $\mathrm{CD}^{+} \mathrm{T}$ cells, IFN- $\gamma^{+} \mathrm{CD} 8^{+}$and $\mathrm{CD} 4^{+} \mathrm{T}$ cells, $\mathrm{T}_{\mathrm{CM}}$ cells, and $\mathrm{T}_{\mathrm{EM}}$ cells in Hepa 1-6 tumors. Moreover, the combination of AZD6738 with radioimmunotherapy led to a descending trend in the number of TIL Tregs and exhausted T cells. Thus, AZD6738 significantly improved the tumor immune microenvironment following radioimmunotherapy. In addition, AZD6738 caused the similar immunophenotype in mice spleens. As a consequence, compared with radioimmunotherapy, AZD6738 plus radioimmunotherapy displayed better therapeutic efficacy in inhibiting tumor growth, prolonging survival, and preventing recurrence in tumor-bearing mice.
Our findings have a high clinical significance. Based on preliminary translational observations, our work raised the possibility that AZD6738 might be a potential synergistic modality for radioimmunotherapy in HCC. Remarkedly, this study provides a basis for future clinical human studies into the treatment of HCC.

\section{Author affiliations}

${ }^{1}$ Department of Radiation Oncology, Southern Medical University Nanfang Hospital, Guangzhou, Guangdong, China

${ }^{2}$ Hepatology Unit and Department of Infectious Diseases, Southern Medical University Nanfang Hospital, Guangzhou, Guangdong, China

${ }^{3}$ Department of Stomatology, No 2 Hospital of Baoding, Baoding, Hebei, China

Correction notice Since the online publication of this article, it was noticed that author Jingyuan Sun was missing from the corresponding author list. This has now been corrected.

Acknowledgements The authors would like to thank Jun Zhao (Sun Yat-Sen University) for her technical support.

Contributors $\mathrm{CC}$ and JS designed and guided the research. HS and YH performed most of the experiments. ZZ and MS wrote the manuscript. PZ, JW, and HW contributed with material support. ZG and WZh analyzed the data. WD did most of the revised work. All authors reviewed and approved the final manuscript.

Funding This work was supported by the National Nature Science Foundation of China (Grant Nos. 81702390, 81903133), Natural Science Foundation of Guangdong Province (Grant Nos. 2017A030310105, 2018A030313398) and Guangzhou Technology Project (No. 201906010087).

Competing interests No, there are no competing interests.

\section{Patient consent for publication Not required.}

Ethics approval All experimental procedures were approved by Southern Medical University Animal Management and Use Committee, and performed in accordance with all applicable international, national, and institutional guidelines for the care and use of animals.

Provenance and peer review Not commissioned; externally peer reviewed.

Data availability statement All data relevant to the study are included in the article or uploaded as supplementary information. The data generated and/or analyzed during the current study are available on reasonable request from the corresponding author.

Open access This is an open access article distributed in accordance with the Creative Commons Attribution 4.0 Unported (CC BY 4.0) license, which permits others to copy, redistribute, remix, transform and build upon this work for any purpose, provided the original work is properly cited, a link to the licence is given, and indication of whether changes were made. See https://creativecommons.org/ licenses/by/4.0/.

\section{ORCID iD}

Chuanhui Cao http://orcid.org/0000-0002-9793-0305

\section{REFERENCES}

1 Siegel RL, Miller KD, Jemal A, et al. Cancer statistics, 2015. CA Cancer J Clin 2015;65:5-29.

2 Zhang Y, Chen L-H, Wang L, et al. Radiation-Inducible PTEN expression radiosensitises hepatocellular carcinoma cells. Int $J$ Radiat Biol 2010;86:964-74.

3 Kang J-K, Kim M-S, Cho CK, et al. Stereotactic body radiation therapy for inoperable hepatocellular carcinoma as a local salvage treatment after incomplete transarterial chemoembolization. Cancer 2012;118:5424-31.

4 Bujold A, Massey CA, Kim JJ, et al. Sequential phase I and II trials of stereotactic body radiotherapy for locally advanced hepatocellular carcinoma. J Clin Oncol 2013;31:1631-9.

5 Gurtner K, Kryzmien Z, Koi L, et al. Radioresistance of KRAS/TP53mutated lung cancer can be overcome by radiation dose escalation or EGFR tyrosine kinase inhibition in vivo. Int J Cancer 2019. doi:10.1002/ijc.32598. [Epub ahead of print: 29 Jul 2019]. 
6 Chen S-W, Lin L-C, Kuo Y-C, et al. Phase 2 study of combined sorafenib and radiation therapy in patients with advanced hepatocellular carcinoma. Int J Radiat Oncol Biol Phys 2014;88:1041-7.

7 El-Khoueiry AB, Sangro B, Yau T, et al. Nivolumab in patients with advanced hepatocellular carcinoma (CheckMate 040): an open-label, non-comparative, phase 1/2 dose escalation and expansion trial. Lancet 2017;389:2492-502.

8 Zhu AX, Finn RS, Edeline J, et al. Pembrolizumab in patients with advanced hepatocellular carcinoma previously treated with sorafenib (KEYNOTE-224): a non-randomised, open-label phase 2 trial. Lancet Oncol 2018;19:940-52.

9 Kim K-J, Kim J-H, Lee SJ, et al. Radiation improves antitumor effect of immune checkpoint inhibitor in murine hepatocellular carcinoma model. Oncotarget 2017;8:41242-55.

10 Burnette BC, Liang $\mathrm{H}$, Lee $\mathrm{Y}$, et al. The efficacy of radiotherapy relies upon induction of type I interferon-dependent innate and adaptive immunity. Cancer Res 2011;71:2488-96.

11 Barber GN. Sting: infection, inflammation and cancer. Nat Rev Immunol 2015;15:760-70.

12 Gupta A, Probst HC, Vuong V, et al. Radiotherapy promotes tumorspecific effector CD8+ T cells via dendritic cell activation. J Immunol 2012;189:558-66.

13 Lee Y, Auh SL, Wang Y, et al. Therapeutic effects of ablative radiation on local tumor require CD8+ T cells: changing strategies for cancer treatment. Blood 2009;114:589-95.

14 Reits EA, Hodge JW, Herberts CA, et al. Radiation modulates the peptide repertoire, enhances $\mathrm{MHC}$ class I expression, and induces successful antitumor immunotherapy. J Exp Med 2006;203:1259-71.

15 Sato H, Niimi A, Yasuhara T, et al. Dna double-strand break repair pathway regulates PD-L1 expression in cancer cells. Nat Commun 2017;8:8.

16 Vendetti FP, Karukonda P, Clump DA, et al. Atr kinase inhibitor AZD6738 potentiates CD8+ T cell-dependent antitumor activity following radiation. J Clin Invest 2018;128:3926-40.

17 Dillon MT, Bergerhoff KF, Pedersen M, et al. Atr inhibition potentiates the radiation-induced inflammatory tumor microenvironment. Clin Cancer Res 2019;25:3392-403.

18 Wherry EJ, Kurachi M. Molecular and cellular insights into T cell exhaustion. Nat Rev Immunol 2015;15:486-99.

19 Blackburn SD, Shin H, Haining WN, et al. Coregulation of CD8+ cell exhaustion by multiple inhibitory receptors during chronic viral infection. Nat Immunol 2009;10:29-37.

20 Sakuishi K, Apetoh L, Sullivan JM, et al. Targeting Tim-3 and PD-1 pathways to reverse $\mathrm{T}$ cell exhaustion and restore anti-tumor immunity. J Exp Med 2010;207:2187-94.

21 Fourcade J, Sun Z, Benallaoua M, et al. Upregulation of Tim-3 and PD-1 expression is associated with tumor antigen-specific CD8+ T cell dysfunction in melanoma patients. J Exp Med 2010;207:2175-86.

22 Liu $\mathrm{H}$, Wang $\mathrm{H}$, Wu J, et al. Lymphocyte nadir predicts tumor response and survival in locally advanced rectal cancer after neoadjuvant chemoradiotherapy: immunologic relevance. Radiother Oncol 2019;131:52-9.
23 Deng L, Liang H, Burnette B, et al. Irradiation and anti-PD-L1 treatment synergistically promote antitumor immunity in mice. J Clin Invest 2014;124:687-95.

24 Kachikwu EL, Iwamoto KS, Liao Y-P, et al. Radiation enhances regulatory $\mathrm{T}$ cell representation. Int $J$ Radiat Oncol Biol Phys 2011;81:1128-35.

25 Dovedi SJ, Adlard AL, Lipowska-Bhalla G, et al. Acquired resistance to fractionated radiotherapy can be overcome by concurrent PD-L1 blockade. Cancer Res 2014;74:5458-68.

26 Zhang W, Song Z, Xiao J, et al. Blocking the PD-1/PD-L1 axis in dendritic cell-stimulated cytokine-induced killer cells with pembrolizumab enhances their therapeutic effects against hepatocellular carcinoma. J Cancer 2019;10:2578-87.

27 Newton JM, Hanoteau A, Liu H-C, et al. Immune microenvironment modulation unmasks therapeutic benefit of radiotherapy and checkpoint inhibition. J Immunother Cancer 2019;7:216.

28 Theelen WSME, Peulen HMU, Lalezari F, et al. Effect of pembrolizumab after stereotactic body radiotherapy vs pembrolizumab alone on tumor response in patients with advanced non-small cell lung cancer: results of the PEMBRO-RT phase 2 randomized clinical trial. JAMA Oncol 2019. doi:10.1001/ jamaoncol.2019.1478. [Epub ahead of print: 11 Jul 2019].

29 Twyman-Saint Victor C, Rech AJ, Maity A, et al. Radiation and dual checkpoint blockade activate non-redundant immune mechanisms in cancer. Nature 2015;520:373-7.

30 Azad A, Yin Lim S, D'Costa Z, et al. Pd-L1 blockade enhances response of pancreatic ductal adenocarcinoma to radiotherapy. EMBO Mol Med 2017;9:167-80.

31 Choi C, Yoo GS, Cho WK, et al. Optimizing radiotherapy with immune checkpoint blockade in hepatocellular carcinoma. World $\mathrm{J}$ Gastroenterol 2019;25:2416-29.

32 Hui R, Özgüroğlu M, Villegas A, et al. Patient-Reported outcomes with durvalumab after chemoradiotherapy in stage III, unresectable non-small-cell lung cancer (Pacific): a randomised, controlled, phase 3 study. Lancet Oncol 2019;20:1670-80.

33 Shaverdian N, Lisberg AE, Bornazyan K, et al. Previous radiotherapy and the clinical activity and toxicity of pembrolizumab in the treatment of non-small-cell lung cancer: a secondary analysis of the KEYNOTE-001 phase 1 trial. Lancet Oncol 2017;18:895-903.

34 Galon J, Costes A, Sanchez-Cabo F, et al. Type, density, and location of immune cells within human colorectal tumors predict clinical outcome. Science 2006;313:1960-4.

35 Chen L, Shen Z. Tissue-Resident memory T cells and their biological characteristics in the recurrence of inflammatory skin disorders. Cell Mol Immunol 2020;17:64-75.

36 Tu X, Kahila MM, Zhou Q, et al. Atr inhibition is a promising radiosensitizing strategy for triple-negative breast cancer. $\mathrm{Mol}$ Cancer Ther 2018;17:2462-72.

37 Gomes LR, Rocha CRR, Martins DJ, et al. ATR mediates cisplatin resistance in 3D-cultured breast cancer cells via translesion DNA synthesis modulation. Cell Death Dis 2019;10:459.

38 Wengner AM, Siemeister G, Lücking U, et al. The novel ATR inhibitor Bay 1895344 is efficacious as monotherapy and combined with DNA damage-inducing or repair-compromising therapies in preclinical cancer models. Mol Cancer Ther 2020;19:26-38. 